Journal of Social Sciences 7 (1): 1-5, 2011

ISSN 1549-3652

(C) 2010 Science Publications

\title{
Education to Face the Wicked Challenges of Sustainability
}

\author{
Bland Tomkinson \\ Honorary Visiting Adviser on Pedagogic Development, \\ Faculty of Engineering and Physical Sciences, University of Manchester, \\ PO Box 88, Manchester M60 1QD, United Kingdom
}

\begin{abstract}
Problem statement: The nature of sustainable development requires new paradigms for education. Issues of sustainability are 'wicked problems' that do not lend themselves to conventional didactic approaches. The challenge for higher education is to examine interdisciplinary approaches to global societal responsibility and, within this, issues of education for sustainable development. Approach: A project, sponsored by the Royal Academy of Engineering, developed a course unit in sustainable development across several disciplines. The approach was initially pedagogic in nature, with a strong evaluative theme. At the same time, a Delphi study was undertaken by the same team and this inter-relates with the main project. The focus of the action research was a series of 'wicked' problems that would provide real-world challenges with no simple answers. Results: The project was evaluated in a number of ways, not least the pre-and post-testing of students' attitudes and approaches, but also using nominal group techniques. The project demonstrated that an interdisciplinary PBL approach succeeded in deepening the learning of the students as well as developing key skills. Conclusion: The use of collaborative, group-based approaches, notably PBL, offers a key way of approaching the design of curricula for sustainable development and other areas of global societal responsibility that hinge on 'wicked problems'.
\end{abstract}

Key words: Sustaninable development, Interdisciplinary nature, problem-based, wicked problem, Education for Sustainable Development, teaching and learning, transformative learning, reflective portfolios, Readiness for Inter-Professional Learning (RIPL), Delphi study

\section{INTRODUCTION}

Wals (2009) suggests that the 'nature of ESD [education for sustainable development] demands new perspectives on matters like curriculum, teaching and learning. ESD and SD tend to focus on connections, feedback loops, relationships and interaction. Yet dominant educational structures are based on fragmentation rather than connections and synergy'

Many projects to embed sustainability in the curriculum start with development within the discipline but the concern here was with the complexity of world problems - ones that are never completely solved. As expressed in the report of the Brundtland (1987) Commission, these include:

- The burden of debt in the developing world, inequitable commercial regulation and a growing number of the world's population living below subsistence level

- Overuse of non-renewable resources, growing competition for limited water supplies and access to water and mineral reserves
- Reduction of biodiversity and increasing desertification

- Pollution of air, water and soil with detrimental influences on the global climate

- Continuing growth of the world's population, with additional economic pressures caused by increased life expectancy

- Increasing extremism, terrorism, armed conflict, mass migration and social disruption

- The threats and consequences of climate change

These might appear to have little to do with some narrow definitions of sustainable development. However, the aspects of societal responsibility were regarded as key by Charles Engel, who was then working on issues of inter-professional education. Politicians and business, he suggested in a keynote address in 2002, have a very short-term view of complex issues and so all the professions need to try to improve and resolve the issues (Engel, 2002). A look at the Brundtland list shows that these are very complex issues that have technological aspects as well as economic, environmental, political and social ones. 
Also, these issues mostly fall within Rittel and Webber (1973) definition of wicked problems, which:

- Have no definitive formulation

- Have no clear end, no 'stopping rule

- Have an answer that is 'good or bad' rather than 'right or wrong

- Have no immediate or ultimate test of their resolution

- Have consequences to every solution - there is no possibility of learning by 'trial and error

- Do not have a well-described set of potential solutions

- $\quad$ Are essentially unique

- May be a symptom of another problem

- Have causes with no unique explanation

- Bring expectations that their 'owners' will find the 'right' answer

Not all of these are needed for a problem to be wicked. Yet it is apparent that traditional monodisciplinary approaches become inappropriate for trying to resolve such problems and also in devising curricula to develop the skills of dealing with them.

The approach taken in Manchester, at that time, was to run a number of interdisciplinary workshops for staff, getting them to focus on difficult issues. For example: the Deputy High Commissioner for New Zealand introduced a workshop on the plight of small island communities. A parallel approach was a weeklong session, under the watchful eye of Charles Engel, for a small group of students drawn from a range of disciplines. The initial problem tackled was one of migration but a final day was spent on the problem of relating these ideas to the curriculum.

The breakthrough came when the UK Royal Academy of Engineering agreed to the use of its Visiting Professorships scheme to support a pilot action research project across a small number of science and engineering students.

\section{MATERIALS AND METHODS}

Having secured internal agreement and some external funding the next step was to build the pilot module. Charles Engel, by then our Visiting Professor, had experience and ideas on how the action research project should operate but also wished to obtain a consensus view. So, a series of working groups was established - a Steering Group, with representation from within and outside the university and four advisory panels with membership from within the Faculty of Engineering and Physical Sciences. These had specific tasks that would not impose a high burden on any participant. The four panels were to:

- Arrive at a working definition of 'Sustainable Development

- Identify abilities and skills that ought to begin to be developed in the pilot module in the context of realistic case studies

- Identify how the learning outcomes of this module might be assessed

- Monitor and evaluate the process of implementing the pilot module, including staff commitment to a new approach to teaching and learning

In addition to being involved in the curriculum design, other important aims of using advisory panels were: to underline the credibility of the professionbased content and, to foster an innovative educational approach throughout the faculty. This approach is described in greater detail in Tomkinson et al. (2007).

The approach taken was one that was studentcentred, problem-based and interdisciplinary. Ideas about the necessity of an interdisciplinary approach in resolving complex issues of sustainable development were surfacing in other quarters at much the same time. Davies and Devlin (2007) point to areas where two or more disciplines combine their expertise to address an area of common concern, such as HIV/AIDS, water crises and climate change. Brand and Karvonen (2007) suggest that sustainable development poses challenges to the discourse of technical experts that do not fit within traditional disciplinary boundaries. Nathalie Lourdel et al. (2005) and colleagues look at a number of approaches to education for sustainable development for engineers and emphasize the need for a holistic approach: "Theoretical classes are not sufficient. It seems important to help them to transpose theoretical knowledge into professional and day-to-day activities.” Some members of the project team were also involved in a Delphi study (Tomkinson et al., 2008) to look at issues of educating engineers for sustainable development.

From the Delphi study, the main challenges appeared to be social and political, rather than technical. There was also a feeling that practicing engineers need to challenge conservative ideas and reluctance to change, in issues of sustainable development. Hence, key responsibilities for young professionals were communication and the raising of awareness, with technical skills taking second place. Chief in terms of tasks for a newly qualified professional was handling complex problems and 
systems modelling to try to cope with this complexity. Individual engineering disciplines identified specific tools and techniques, but the number of respondents in any particular branch of engineering was too small to make clear distinctions. In terms of education, the main conclusion from the study was that sustainable development should be embedded in the curriculum. Also, student-centred learning methods, in particular role play and case studies, were most appropriate. The emphasis on student-centred, experiential methods used in problem-based learning as expounded by Charles Engel and others (Dangerfield et al., 2007) is broadly in line with this view.

The panel advising on skills came up with eighteen potential subjects for case studies or problem scenarios but these were reduced so that:

- Problems should be complex or 'wicked

- Scenarios should be in context for a recent graduate

- Exercises should develop skills in the management of change

- Problems should lead students to identify core principles of sustainable development;

- Exercises should develop professional skills

- Each exercise should build cumulatively on previous ones

- Wherever possible, issues should be current

- Exercises should foster thinking across disciplinary boundaries

The exercises were formulated by a range of experts from within and outside the university, including architects, economists and lawyers, as well as scientists and engineers. These are described in more detail in the report to the Royal Academy of Engineering on the project (Tomkinson, 2009).

At the same time as designing the curriculum, the project team was selecting the students to participate and selecting and training the facilitators for the exercises. A decision was taken to run the first pilot year with six teams of eight students. Four subject disciplines agreed to offer this option: Civil Engineering; Electrical and Electronic Engineering; Environmental Sciences and Mechanical Engineering. Students were selected on a brief statement of intent but with an eye on maintaining a balance between numbers from each discipline. The final groupings also tried to balance gender and national origins (about half of the participants were not from the [name of country]). Facilitators were recruited from post-doctoral researchers who were selected by the sensitivity of their approach during four $2 \mathrm{~h}$ training sessions. The emphasis was on assisting students' independent, selfdirected, learning, not 'teaching'. Facilitators were drawn from a wider range of subject disciplines than the students and also from a wide range of national origins. In their groups, the students undertook five exercises, each spanning two weeks. They were timetabled for 2 hours each Wednesday morning. Each problem scenario resulted in reports from the student groups and these were marked and the results fed back to the students. Only the last of these counted towards their mark for the module. In the first year students also undertook two Modified Essay Questions under examination conditions: this approach is described in Feletti and Engel (1980). In later years this was replaced by an individual reflective portfolio.

\section{RESULTS}

The project was evaluated in a number of ways. During both years that the module ran as a pilot, students and facilitators took part in nominal group processes. Delbecq et al. (1975) and colleagues describe this group-based approach, as well as that of the Delphi technique. The student feedback in both years was very similar, particularly in the 'positives'. The students' top-ranking items in both years were: the interdisciplinary nature of the course unit; the development of teamwork skills; the nature of the facilitation; the realistic content of the module and the methods of assessment. On the 'negative side' students did not like the 9am start and assessment also featured in both years. This was largely because the first four exercises were formative and were not counted as part of the end of year marks.

The facilitators also had similar views between the two years, with problem-based learning, imaginative tasks and communication skills for the students all featuring positively. The interdisciplinary nature of the module and the development of the facilitators' skills in teaching also featured strongly. There was more variety in the negative responses of facilitators between the two years, the principal difference being concern about pay. However, in both years the facilitators wished to see a wider range of disciplines represented in the student group, particularly the lack of any social scientists.

As well as the university's standard student satisfaction questionnaire, a number of instruments were applied, designed to check on the students' development over the duration of the course unit. These were: a student self-perception questionnaire, designed by the university's School of Education; a questionnaire 
based on Mattick and Bligh (2006) Readiness for InterProfessional Learning (RIPL) questionnaire and a shortened from of the ETL learning styles questionnaire (ETL Project, 2005). These were applied at the beginning and end of the unit. The results of the selfperception questionnaire indicated that students felt more confident about their knowledge and skills in this area at the end of the course unit and the learning styles questionnaire also showed an increase in the application of 'deep' learning. However, the RIPL questionnaire results showed no significant differences, largely as a result of very high initial scores. The university's standard questionnaires showed very high student satisfaction on most items in the first year and only slightly less satisfaction in the second: the few dimensions on which the course unit did not score well were those where the questions asked were inappropriate to this approach to learning (e.g., questions about 'lectures'). The learning styles questionnaire has also been used in the second and third years: at the time of writing, the analysis is not yet complete but the second year results were similar to those for the first year. In the third year of operation there was also a small questionnaire study of facilitation styles but the analysis of this has yet to be completed. In the second and third years of operation, the use of reflective portfolios also revealed changes in student attitudes as well as in the development of skills-for example in self-directed learning and research.

This was a successful start to a single course unit and it was Highly Commended in the UK's 2008 Green Gown Awards, for its transformative approach to education. Mezirow (2003) describes transformative learning as 'learning that transforms problematic frames of reference' which he suggests should 'make them more inclusive, discriminating, open, reflective and emotionally able to change'. Sterling (2004) suggests that transformative learning enables the student to move out of his or her paradigm and is essential for education in sustainable development "It is not then just a matter of intellectual or conceptual learning, but engages our emotional and intuitive selves as well”. The UNESCO DESD review (Wals, 2009) suggests that "ESD calls for new kinds of learning that are not so much of a transmissive nature (ie learning as reproduction) but rather of a transformative nature (ie learning as change). The latter requires permeability between disciplines, schools and the wider community and between cultures, along with the capacity to integrate, connect, confront and reconcile multiple ways of looking at the world.” Certainly, the interdisciplinary and experiential approach adopted in the project seeks to engage the whole person and to enable the student to 'think outside the box'. The cross-cultural nature of the student groups, part of the reality of the student body in Manchester, added an extra dimension to the experience. Major difficulties were in finding a suitable slot in the timetable, since students from many different programmes needed to be together for two hours a week and in the internal transfer of funds. During a pilot project with small numbers and some external funding the issue of course costs was not a major issue but as the course expanded, at the same time as departmental budgets were being trimmed, financial support became a major problem. With a crossdepartmental course of this type a strong funding model (top-slicing) is needed from the outset.

\section{CONCLUSION}

The evaluation of the project suggests that this is not only a valid approach to education for sustainable development but also that the approach is perhaps the best paradigm in this context. Moreover, the ideas that this project embraces are capable of being used much more widely. They are not solely confined to educating engineers and scientists for sustainable development. The core approaches and ideas could prove a useful starting point in redesigning university programmes, based on our curriculum design for active, contextual, cumulative, integrated, interdisciplinary, collaborative and reflective learning. Since the two pilot years, the module has gone on to recruit students from a much wider range of disciplines. In a slightly modified form, it is run as an optional module for students on taught Masters degree and similar module is run in Humanitarian Aid. Initial explorations have also been carried out to see if the approach can be developed through electronic means, so enabling participation by students based in different countries. This is being followed up by a further pilot project involving the Universities of Keele and Staffordshire as well as Manchester.

The report of the study (Tomkinson, 2009), together with its appendices, is designed to enable others to replicate the approach to see to what extent the educational approach is transferable. The extension of the pilot study across more disciplines, across different study levels and to adjacent problem areas, indicates that the approach is highly appropriate for the development of students to cope with complex societal issues and other wicked problems. 


\section{REFERENCES}

Brand, R. and A. Karvonen, 2007. The ecosystem of expertise: Complementary knowledge's for sustainable development. Sustainability: Sci. Practice Policy, 3: 21-31. http://ejournal.nbii.org/archives/vol3iss1/0601004.brand.html

Brundtland, G., 1987. Our Common Future: The World Commission on Environment and Development. 1st Edn., Oxford University Press, Oxford, ISBN: 978-0-19-282080-8 passim, pp: 257.

Davies, M. and M. Devlin, 2007. Interdisciplinary higher education: Implications for teaching and learning. The University of Melbourne http://www.cshe.unimelb.edu.au/resources_teach/c urriculum_design/docs/InterdisciplinaryHEd.pdf

Delbecq, A., A. Van de Ven and D. Gustafson, 1975. Group Techniques for Program Planning: A Guide to Nominal Group and Delphi Processes. 1st Edn., Foresman and Company, Glenview, Scott, ISBN: 0673075915, pp: 174.

Dangerfield, P., T. Dornan, C. Engel, G. Maudsley and J. Naqvi et al., 2007. A whole system approach to problem-based learning in dental, medical and veterinary sciences-a guide to important variables. University of Newcastle, Australia. http://www.newcastle.edu.au/Resources/Faculties/ Faculty\%20of\%20Health/documents/A\%20Whole \%20System\%20Approach\%20Amended\%208\%20 March\%202011.pdf

Engel, C.E., 2002. Towards a European approach to an enhanced education of the health professionals in the 21st century. Centre for Higher Education Studies, Institute of Education, London. http://www.caipe.org.uk/silo/files/towards-aeuropean-approach.pdf

ETL Project, 2005. Shortened experiences of teaching and learning questionnaire. Universities of Edinburgh. http://www.etl.tla.ed.ac.uk/docs/SETLQ.pdf

Feletti, G. and C. Engel, 1980. The modified essay question for testing problem-solving skills. Med. J. Australia, 1: 79-80. PMID: 7360093
Lourdel, N., N. Gondran, V. Lafores and C. Brodhag, 2005. Introduction of sustainable development in engineers' curricula: Problematic and evaluation methods. Int. J. Sustain. Higher Edu., 6: 254-264. DOI: 10.1108/14676370510607223

Mattick, K. and J. Bligh, 2006. Getting the measure of inter-professional learning. Med. Educ., 40: 399-400. DOI: 10.1111/J.1365-2929.2006.02487.X

Mezirow, J., 2003. Transformative leaning as discourse. J. Trans. Educ. 1: 58-63. DOI: $10.1177 / 1541344603252172$

Rittel, H. and M. Webber, 1973. Dilemmas in a general theory of planning. Policy Sci., 4: 155-169. DOI: 10.1007/BF01405730

Sterling, S., 2004. Higher Education, Sustainability and the Role of Systemic Learning. In: Higher Education and the Challenge of Sustainability, Corcoran, P. and A. Wals (Eds.). Dordrecht, Springer, ISBN: 978-1402021343, pp: 49-70.

Tomkinson, B., 2009. Educating engineers for sustainable development: Final report of a royal academy of engineering sponsored pilot study. University of Manchester. http://www.eps.manchester.ac.uk/tlc/sd/documents/ RAEng_Report.pdf

Tomkinson, B., C. Engel, R. Tomkinson and H. Dobson, 2007. Introducing an Interdisciplinary Professional Course on Sustainable Development into Engineering Programmes. In: Innovations 2007: World Innovations in Engineering Education and Research, Aung, W. et al. (Eds.). Arlington VA, iNEER, ISBN: 978-0-9741252-6-8, pp: 65-75.

Tomkinson, R., C. Engel, B. Tomkinson and A. Lawson, 2008. Engineering Subject Centre Mini-Project Report: Education for Sustainable Development in Engineering Report of a Delphi Consultation. The Higher Education Academy. http://www.engsc.ac.uk/downloads/scholarart/delp hi-consultation.pdf

Wals, A., 2009. Learning for a sustainable worldreview of contexts and structures for education for sustainable development. UNESCO. http://unesdoc.unesco.org/images/0018/001849/18 4944e.pdf 